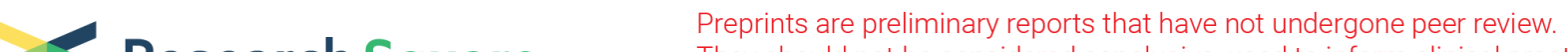 Research Square
They should not be considideded conclusivive, used to inform clinical practice,
or referenced by the media s validated information.
}

\section{FGF21 Promotes Proliferation and Estradiol Synthesis in Porcine Granulosa Cells}

\section{Yamei Hu}

Northwest A\&F University: Northwest Agriculture and Forestry University

Xiaoge Zhou

Northwest A\&F University: Northwest Agriculture and Forestry University

Shengjie Shi

Northwest A\&F University: Northwest Agriculture and Forestry University

Yankun Li

Northwest A\&F University: Northwest Agriculture and Forestry University

\section{Liang Huang}

Northwest A\&F University: Northwest Agriculture and Forestry University

Lei Gao

Northwest A\&F University: Northwest Agriculture and Forestry University

\section{Weijun Pang}

Northwest A\&F University: Northwest Agriculture and Forestry University

Gongshe Yang ( $\square$ gsyang@nwafu.edu.cn )

NWAFU

Guiyan Chu

Northwest A\&F University: Northwest Agriculture and Forestry University

\section{Research}

Keywords: Estradiol, FGF21, Granulosa cells, Ovary, Pig

Posted Date: July 30th, 2021

DOI: https://doi.org/10.21203/rs.3.rs-746628/v1

License: (c) (1) This work is licensed under a Creative Commons Attribution 4.0 International License.

Read Full License 


\section{Abstract}

Background: The proliferation and estradiol synthesis in granulosa cells (GCs) directly promotes follicular development. Previous studies had found that FGF21 regulated the hypothalamic-pituitary-gonad axis in response to the control of fertility. However, the functions and mechanisms of FGF21 in GCs are unclear.

Results: Here, we found that the mRNA and protein levels of FGF21 in the ovarian tissue of high-yielding sows (Sus scrofa) was higher than that in low-yielding sows. Moreover, FGF21 was predominantly expressed in porcine GCs. Additionally, ELISA assay showed estradiol was significantly increased when overexpression of FGF21 in porcine GCs. Meanwhile, overexpressed FGF21 up-regulated both the mRNA and protein levels of key estradiol synthesis-related genes in porcine GCs, including StAR, CYP11A1 and CYP19A1. Corresponsingly, knockdown FGF21 inhibited estradiol levels and its synthesis-related genes expression. Besides, overexpression of FGF21 promoted the proliferation of porcine GCs, displayed as increasing the percentage of S-phase cells in cell cycle and EdU positive cells, including cell viability, and upregulated cell cycle genes, including cell cycle protein B (Cyclin B) and protein E (Cyclin E). Corresponsingly, knockdown FGF21 in porcine GCs suppressed the cell cycle and cell viability, as well as EdU positive cell number.

Conclusions: These findings highlight that FGF21 is associated with the development of GCs and may be a novel underlying regulator of porcine follicular development.

\section{Background}

Fibroblast growth factor 21(FGF21) is a stress-inducible hormone that has important roles in regulating energy balance and glucose and lipid homeostasis[1], which is mainly expressed in liver and muscle. The family plays important roles in the endocrine-based regulation of metabolism [1-3]. Metabolism enhances supports cell proliferation and growth[4]. Overexpressing FGF21 promotes non-small cell lung cancer growth and migration significantly[5]. It is not a unique instance, but has its counterpart. FGF21 inhibitor suppresses the proliferation and migration of human umbilical vein endothelial cells through the eNOS/PI3K/AKT pathway[6]. Besides, FGF21 acts on adipocytes to promote the expression and secretion of CCL11 via activation of ERK1/2, which drives recruitment of eosinophils into scWAT, leading to increases in accumulation of M2 macrophages, and proliferation and commitment of adipocyte precursors into beige adipocytes[7]. These results suggest the important role of FGF21 in cell growth and proliferation.

In mammals, it is widely known that GCs proliferation plays a vital regulatory role in deciding the fate of follicles and follicular maturation[8-10]. One of mainly functions of GCs proliferation is to secrete estrogens. Estradiol is the most active form of natural estrogens and is known to play important roles in female reproduction [11]. Estradiol derived from cholesterol. After binding to lipoprotein receptors, cholesterol is taken up by steroidogenic cells, stored, and moved to the sites of steroid synthesis[12]. The rate-limiting step in steroid production is StAR transport cholesterol from the cytosol to the inner 
membrane of the mitochondrion, where the cytochrome P450 enzymes that catalyze the cleavage of the side chain of cholesterol are located. where it is converted to pregnenolone by CYP11A1 [13]. Aromatase CYP19A1 transforms testosterone into estradiol in GCs[13, 14]. Furthermore, estrogens produced in GCs are suggested to support the survival and proliferation of GCs and facilitate the maturation of follicles[15]. Studies shown that the proliferation of GCs is also regulated by cell cycle genes, including Cyclin B, Cyclin E, Cyclin D, CDKs and p27[16, 17].

The development of mammalian follicles is a key process in the ovary, and the proliferation and growth of GCs directly promotes follicular development [18]. As they proliferate and differentiate during follicular development, GCs can synthesize a variety of hormones and growth factors, and they express their receptors $[19,20]$. These substances regulate the growth, differentiation and maturation of follicular inner membrane cells and oocytes through gap junctions, and then, they regulate follicular development[21]. Therefore, the normal functions of GCs to proliferate and secrete hormones are essential for the continuous development of follicles.

Recent studies have shown that FGF21 regulated female reproduction through neuroendocrine pathways [22]. However, other data indicated that FGF21 has no direct effect on female fertility in mice [23].

Interestingly, FGF21 cooperates with adiponectin to play a beneficial role in preserving mouse primordial follicles in females fed a low-protein diet [24]. Besides, studies also have revealed that FGF21 is associated with the cell growth and proliferation $[4,6,25,26]$. However, no studies have focused on the FGF21's expression level and biologically functions in porcine GCs. Therefore, whether and how FGF21 affects follicular development still requires further investigation. Here, porcine ovaries were used to study the regulatory mechanism of FGF21 in ovarian granulosa cell proliferation and hormone secretion. The results increase our understanding of FGF21's effects on follicular development.

\section{Materials And Methods}

\section{Ovary collection from high- and low-yielding sows (Sus scrofa)}

Litter size records (a total of 8,567 parities) at Hanshiwei Food Co., Ltd. (Dahua pig farm, Guangxi, China) from 2016 to 2018 were collected, sorted and analyzed. The low-yielding group was defined as less than 9.3 heads per litter, and the high-yielding group was defined as more than 14.7 heads per litter [16]. The ovarian tissues of three high- and low-yielding 'Yorkshire' $\times$ 'Landrace' sows having the same physiological status and similar body weights were collected.

\section{Ovarian tissues and immunohistochemistry}

Fresh ovarian tissues were removed, washed with normal saline, and fixed with paraformaldehyde, at greater than 7 to 10 times the volume of the ovaries, for $24 \mathrm{~h}$ at room temperature. They were then 
embedded in paraffin and sliced into sections for HE staining. The largest cross sections were selected for FGF21 (sc-81946,1/1000) immunohistochemical staining.

\section{Granulosa cells isolation and culture}

Fresh porcine ovaries $(n=30)$ from cyclic sows were collected and immediately placed in a saline solution containing $100 \mathrm{IU} / \mathrm{mL}$ of double-antibody (cyano-streptomycin) at $37^{\circ} \mathrm{C}$. These ovaries were shipped back to the laboratory within $2 \mathrm{~h}$ and cleaned in a thermostatic saline solution. The antral follicles $₫ 3-6$ $\mathrm{mm}$ diameters囚located on the ovarian surface were punctured to collect follicular fluid. The cumulusoocyte complex was removed using a 70-mm cell strainer to obtain GCs. GCs were resuspended in DMEM/F12 (Servicebio, Wuhan, China) containing 3\% BSA, and then, they were inoculated into a cell culture well and cultured in a cell incubator with $5 \% \mathrm{CO}_{2}$ at $37{ }^{\circ} \mathrm{C}$ [27].

\section{Transfection of FGF21 siRNA and FGF21 recombinant protein treatment}

To study the effects of FGF21 on proliferation and hormone synthesis in GCs, transfection experiments were performed at a cell density of $40 \%$ to $50 \%$. All the transfection procedures were performed with Xtreme-GENE siRNA Transfection Reagent (Roche) in accordance with the manufacturer's instructions. In addition, GCs were treated with different FGF21 recombinant protein concentrations $(0.1,1$ and 10 $\mathrm{ng} / \mathrm{mL}$ ). After transfection and recombinant protein exposure for $24 \mathrm{~h}$, the culture supernatants and cells were collected for subsequent experiments.

\section{Total RNA extraction, RNA reverse transcription and RT- qPCR}

Total RNAs from different cells were extracted using Trizol (TaKaRa, Otsu, Japan), and the concentrations were measured using a NanoDrop 2000 (Thermo, Waltham, MA, USA). Total RNA (500 ng) was reverse transcribed to cDNA using a reverse transcription kit (TaKaRa). Quantitative real-time (RT) -qPCR was performed on a StepOne Real-Time PCR Machine ( $A B I$, Carlsbad, CA, USA). The relative level of mRNA was standardized to $\beta$-actin and calculated using the 2- $\Delta \Delta$ Ct method. Primer sequences used for RTqPCR are listed in Table 1.

Table 1

RT-qPCR primer sequences used in the study (Sus scrofa). 


\begin{tabular}{lll} 
Gene Name & Forward $\left(5^{\prime}{ }^{\prime}{ }^{\prime}\right)$ & Reverse $\left(5^{\prime}\right.$-3') \\
\hline FGF21 & CCTGAAGCCAGGGGTCATTC & CGATCCGTACAGTCTCCCGT \\
\hline StAR & CGTTTAAGCTGTGTGCTGGG & TCCATGACCCTGAGGTTGGA \\
\hline 33-HSD & TCTTGTCTGCTTCTCGCCAC & CAACTGAGACTTGGGTGCCA \\
\hline CYP11A1 & GGGCAACCCATTTCCTACCA & CGAGCACTGGTGGTACAGAC \\
\hline CYP19A1 & TCCGCAATGACTTGGGCTAC & GCCTTTTCGTCCAGTGGGAT \\
\hline Cyclin B & AATCCCTTCTTGTGGTTA & CTTAGATGTGGCATACTTG \\
\hline Cyclin D & TACACCGACAACTCCATCCG & GAGGGCGGGTTGGAAATGAA \\
\hline Cyclin E & AGAAGGAAAGGGATGCGAAGG & CCAAGGCTGATTGCCACACT \\
\hline p21 & ACGTCTCAGGAGGACCATGT & AGAAGATCAGCCGGCGTTTG \\
\hline B-actin & GGACTTCGAGCAGGAGATGG & AGGAAGGAGGGCTGGAAGAG \\
\hline SR-BI & GCTGTTCATCCCCATCGTCT & GGCCTGAATGGCCTCCTTAT \\
\hline SREBP2 & CTCACCTTCCTGTGCCTCTC & CCAGAAGGTGACTGAGGAGC
\end{tabular}

\section{Western blotting}

The GCs were washed three times with PBS ( $\mathrm{pH}=7.4$ ), and then, $120 \mu \mathrm{L}$ RIPA (Beyotime, Shanghai, China) supplemented with protease inhibitors (Pierce, Rockford, IL, USA) was added to each well of the 6-well plate. Afterward, samples were lysed on ice for $20 \mathrm{~min}$, collected and centrifuged at $12,000 \times \mathrm{g}$ for $10 \mathrm{~min}$ at $4^{\circ} \mathrm{C}$. A BCA protein assay kit (Cwbio, Beijing, China) was used to determine protein concentrations. A $1 / 4$ volume of $5 \times$ loading buffer (Cwbio, Beijing, China) was added to an aliquot of the supernatant, and a $20-\mu$ g protein sample was separated on a $10 \%$ SDS-polyacrylamide gel. After electrophoresis, the samples were transferred to the polyvinylidene fluoride (PVDF) membranes (CST, Boston, MA, USA), which were blocked with $5 \%$ skimmed milk powder for $2 \mathrm{~h}$. The membranes were then incubated at $4^{\circ} \mathrm{C}$ overnight with primary antibodies (1:1000) against StAR, CYP11A1, CYP19A1, 3 $\beta$-HSD, $\beta$-actin, SR-BI, SREBP2 and p21 (Abcam, Cambridge, UK), as well as against Cyclin B, Cyclin D, Cyclin E and FGF21(Santa Cruz, CA, USA). The membranes were placed in secondary antibody (Boster, Wuhan, China) solutions and incubated at $4^{\circ} \mathrm{C}$ for $2 \mathrm{~h}$. Finally, the signals were detected using a gel imaging system (BioRad, CA, USA), and the intensity levels of the bands were measured using Image $\mathrm{J}$ software. All the experiments were repeated at least three times and mean values were derived.

\section{Measurement of estradiol and progesterone in the culture medium}


The collected supernatant was centrifuged at $4^{\circ} \mathrm{C}$ for $10 \mathrm{~min}$, and then, porcine estradiol and progesterone enzyme-linked immunoassays (ELISAs) were performed in accordance with the kit's instructions (Nanjing Jiancheng Bioengineering Institute, Nanjing, China).

\section{EdU imaging assay}

GCs were seeded in 96-well plates at a concentration of per $2 \times 10^{3}$ concentration per well. After treating the cells with FGF21 siRNA (si-FGF21) and recombinant protein (rFGF21) for $24 \mathrm{~h}$, they were incubated with $50 \mu \mathrm{M}$ EdU (RiboBio, Guangzhou, China) for $2 \mathrm{~h}$. The cells were washed twice with PBS, fixed in $4 \%$ paraformaldehyde for $30 \mathrm{~min}$, neutralized with $2 \mathrm{mg} / \mathrm{mL}$ glycine for $5 \mathrm{~min}$ and permeabilized with $0.5 \%$ TritonX-100 for $10 \mathrm{~min}$. Afterward, $100 \mu \mathrm{L}$ of $1 \mathrm{X}$ Apollo ${ }^{\circledR}$ staining reaction solution was added to each well, and the plates were protected from light at room temperature while on a shaker for $30 \mathrm{~min}$. The reaction solutions were discarded after staining. Then, $100 \mu \mathrm{L}$ of penetrant $(0.5 \%$ TritonX-100 in PBS) was added to each well, and the samples were washed twice on a shaker for $10 \mathrm{~min}$ each time.Then, the penetrant was discarded. Finally, $100 \mu \mathrm{L} 1 \mathrm{X}$ Hoechst 33342 was added to each well to stain the nuclei. The stained cells were observed using a Nikon TE2000 microscope (Nikon, Tokyo, Japan) and the data were analyzed using Image $\mathrm{J}$ software.

\section{Cell counting kit 8(CCK8) analysis}

GCs were seeded in 96-well plates at a $2 \times 10^{3}$ concentration per well. After treating the cells with FGF21 siRNA and rFGF21 for $24 \mathrm{~h}, 10 \mu \mathrm{L}$ CCK8 reagent was added to each well and incubated for $3 \mathrm{~h}$ at $37^{\circ} \mathrm{C}$. Absorbance was measured at $450 \mathrm{~nm}$ using Vector 5 (Waltham, MA, USA).

\section{Flow cytometry}

GCs were seeded in 6-well plates at a $4 \times 10^{5}$ concentration per well. The cells were treated with si-FGF21 and rFGF21 for $24 \mathrm{~h}$, and then, cells were digested with $0.25 \%$ trypsin and collected in $10 \mathrm{~mL}$ centrifuge tubes. The tubes were centrifuged at $1,200 \times \mathrm{g}$ for $10 \mathrm{~min}$, and the supernatants were discarded. The cells were resuspended in $70 \%$ cold ethanol and placed overnight at $4^{\circ} \mathrm{C}$. The cells were washed twice and stained with $50 \mathrm{mg} / \mathrm{mL}$ propidium iodide $(\mathrm{PI})$ for $30 \mathrm{~min}$. Finally, the cell cycles of the porcine GCs were analyzed using flow cytometry (Becton Dickinson, Franklin Lakes, NJ, USA).

\section{Statistical analysis}

Each experiment was conducted at least three times and data for continuous variables are presented as mean values with standard errors of the mean (SEM). Statistical comparisons of mean values between 
groups were performed using t-test and multiple comparisons were performed using a one-way analysis of variance (ANOVA). Differences were considered to be statistically significant at a $P$-value was $<0.05$.

\section{Results}

\section{FGF21 highly expression in high-yielding porcine ovaries}

The FGF21 expression levels in ovaries of high-yielding and low-yielding sows was examined. The FGF21 mRNA and protein levels in the ovaries of high-yielding sows were significantly higher than in low-yielding sows (Fig. 1A, B). Immunohistochemical staining revealed that FGF21 was mainly expressed in GCs (Fig. 1D). To further confirm whether FGF21 was associated with follicular development, GCs in porcine ovarian follicles of different diameters were isolated and cultured, and the FGF21 mRNA levels were detected. The expression of FGF21 in GCs of large follicles (diameters $>6 \mathrm{~mm}$ ) was significantly higher than in small follicles (diameters $<3 \mathrm{~mm}$ ) (Fig. 1C). The results suggest that FGF21 is expressed in porcine ovarian GCs.

\section{Knockdown FGF21 inhibites granulosa cells estradiol synthesis}

During follicular development, the main function of GCs is to secrete estradiol. To investigate the role of FGF21 in the estradiol synthesis of GCs, FGF21 knockdown experiments were carried out in GCs. A successful FGF21 knockdown was produced (Fig. 2A). An ELISA of the FGF21 knockdown's medium supernatant revealed that the estradiol content significantly decreased compared with the control (Fig. 2B). This finding indicates that FGF21 plays a role in the estradiol synthesis. To confirm this hypothesis, we detected the mRNA and protein levels of key enzymes in the estradiol synthesis process and found that StAR, CYP11A1 and CYP19A1 mRNA and protein levels were also suppressed in the FGF21 knockdown group (Fig. 2. C-E). These data indicated that knockdown FGF21 could inhibit the synthesis of estradiol in GCs.

\section{Knockdown FGF21 inhibites estradiol synthesis through granulosa cells cholesterol metabolism}

Cholesterol is a precursor required for steroid hormone synthesis. Therefore, to explore the FGF21associated mechanism regulating estradiol synthesis, we determined the cholesterol levels of GCs after the FGF21 knockdown. The FGF21 expression decreased. The estradiol content of GCs decreased significantly (Fig. 3A), and the progesterone content also showed a downward trend (Fig. 3B). At the same time, the triglycerides and cholesterol levels were also determined. There was no change in the triglyceride levels (Fig. 3C), but there was significantly decreased in total cholesterol levels (Fig. 3D). Additionally, bodipy staining was used to observe the neutral lipid droplets contents in GCs. After FGF21 
decreased, neutral lipid droplets contents in the cells increased (Fig. 3E). In addition, the knockdown of FGF21 caused a significant decrease in the level of the cholesterol transport-related protein SREBP2 (Fig. $3 F, G)$. Thus, FGF21 appears to be a potential regulator of estradiol synthesis, functioning partly through cholesterol metabolism.

\section{Overexpression FGF21 promotes the estradiol synthesis in granulosa cells}

To further confirm the effects of FGF21 on estradiol synthesis in GCs, we used different FGF21 recombinant protein concentrations $(0,0.1,1$ and $10 \mathrm{ng} / \mathrm{mL})$ to treat GCs. The $F G F 21$ overexpression was successful (Fig. 4A). Moreover, the estradiol and progesterone contents in the supernatant of the culture medium were detected. FGF21 overexpression significantly increased the estradiol and progesterone levels (Fig. 4B, C). This finding confirmed that FGF21 positively regulated the estradiol content of GCs. Next, we determined the expression levels of the key estradiol synthesis-associated genes StAR, CYP11A1 and CYP19A1. FGF21 recombinant protein overexpression up-regulated these key genes at both the mRNA and protein levels (Fig. 4D-H). Consequently, we hypothesized that FGF21 promotes estradiol synthesis in GCs.

\section{FGF21 promotes granulosa cells proliferation}

During follicular development, GCs secrete estradiol to enhance mitosis[20]. Therefore, we speculated that FGF21's promotive effects on estradiol synthesis are related to GCs proliferation. To verify this hypothesis, FGF21 knockdown and overexpression exprements were carried out in GCs to detect indicators related to cell proliferation. The FGF21 knockdown decreased the number of 5-ethynyl-20depoxyuridine (EdU)-positive cells (Fig. 5A, B). The CCK8 assays showed that the cell viability was consistent with the EdU results (Fig. 5 C). A flow cytometry analysis also indicated that the FGF21 knockdown reduced the proportion of cells in S phase (Fig. 5D, E). Additionally, the FGF21 knockdown decreased the mRNA and protein levels of the proliferation-related genes $C y c l i n B$ and increased the levels of the proliferation suppressor gene p21(Fig. $5 \mathrm{~F}-\mathrm{H}$ ). Furthermore, FGF21 overexpression increased the number of EdU-positive cells (Fig. 6A), the number of cells in S phage (Fig. 6C, D), and mRNA and protein levels of proliferation-related genes (Fig. 6B, E and F). Thus, FGF21 appears to promote GCs proliferation.

\section{Discussion}

In the ovary, the basic functional unit is the ovarian follicle, which consists of an oocyte surrounded by granulosa and theca cells that are essential for normal oocyte development and steroid hormone production[28]. GC proliferation influences steroid hormone synthesis[29, 30]. Here, we found the existence of FGF21 in porcine GCs, which suggested that this molecule is abundantly present in ovarian 
follicles. FGF21, as an endocrine signal, may play an important role in follicular development, including GCs proliferation and steroidogenesis.

In this study, we used high-yield ( $>14.7$ heads/litter) and low-yield ( $<9.3$ heads/litter) ovarian groups of 'Yorkshire' $\times$ 'Landrace' sows to verify that FGF21 was expressed higher in high-yield sows (Fig. 1A-C), which indicated that FGF21 was important for female reproduction. The ovarian immunohistochemistry of FGF21 showed that FGF21 was abundantly expressed in follicular GCs (Fig. 1D). In addition, we isolated and cultured porcine GCs of different diameters and detected FGF21 expression. The FGF21 expression level was higher in larger, compared with smaller follicular GCs (Fig. 1E). In addition, timerestricted feeding improves the reproductive functions of female mice through liver FGF21[31].Furthermore, FGF21 has beneficial effects, which implies that it is a vital positive regulatory factor of follicular development.

We speculated that FGF21 mainly regulates the physiological functions of GCs and plays important roles in follicular development. Steroid hormone production is a major biological function of ovarian GCs. Recently, several studies also have indicated that GCs proliferation influence the synthesis of steroid hormones $[16,29,30]$. In this study, we demonstrated that $F G F 21$ affects estradiol synthesis in porcine GCs. The overexpression of FGF21 increased StAR, CYP11A1 and CYP19A1 expression levels, as well as estradiol productions (Fig. 4B-H), which indicated that FGF21 promotes porcine GCs steroidogenesis.

To further explore the mechanisms of FGF21 in regulating estradiol synthesis in GCs, we tested the content of cholesterol, a precursor substance of estradiol synthesis. There was significantly decreased in the total cholesterol levels (Fig. 3D). However, in addition to mitochondria, steroid hormones are also synthesized in lipid droplets [32]. Bodipy was used to stain the neutral lipid droplets in GCs, but it was found that after knockdown FGF21, the neutral lipid droplets in the cells increased. It may be because after knockdown FGF21 and cell metabolism slows down, resulting in an increase in lipid droplets[33]. However, a large number of lipid droplets will inhibit the synthesis of steroid hormones[34]. In addition, the FGF21 knockdown caused a significant decrease in the protein level of the cholesterol transportrelated gene SREBP2(Fig. 3F, G). Therefore, part of the regulatory effect of FGF21 on granulosa cell's estradiol synthesis may be explained by its effect on cholesterol metabolism. The detailed molecular mechanism of FGF21's regulation of estradiol synthesis still needs further investigation.

A single-layered primordial follicle with flat GCs does not have the ability to synthesize estradiol in vitro; however, the well-developed multilayered and antral follicle, in which the ultrastructural characteristics of the thecal and granulosa cell layers are similar to an adult ovarian follicle, synthesized estradiol in vitro[35]. Estradiol synthesis increases along with the number of GCs. The endocrine role of FGF21 was discovered in 2005, and it acts as a novel metabolic regulator that promotes cell proliferation and growth[7, 36], However, whether FGF21 affected GCs proliferation was unclear. Therefore, we investigated whether FGF21 affects GCs proliferation while promoting estradiol synthesis. Our experimental results indicated that FGF21 promoted proliferation by up-regulating the mRNA and protein levels of $C y c l i n B$ and decreasing the mRNA and protein levels of p21(Fig. 5F-H, Fig. 6E, F ).Cyclin B is a immunohistochemical 
marker of proliferation[37] and p21 is an important member of the cyclin-dependent kinase inhibitor family[38]. These results were consistent with those of previous studies. For example, FGF21 drives oligodendrocyte precursor cell proliferation [39].

\section{Conclusions}

In summary, as shown in Fig. 7, our results showed that FGF21 was highly expressed in porcine ovarian GCs and promoted the proliferation and estradiol synthesis in GCs. They revealed that FGF21 has the potential to directly regulate follicular development, and they provide a theoretical basis for further research on the FGF21-associated regulatory mechanisms of follicular development.

\section{Abbreviations}

DAPI: 4',6-diamodino-2-phenylindole; FGF21: fibroblast growth factor 21; StAR: steroidogenic acute regulatory protein; CYP11A1: cytochrome P450 family 11 subfamily A member 1 ; CYP19A1: cytochrome P450 family 19 subfamily A member 1; 3ß-HSD: hydroxy-delta-5-steroid dehydrogenase,3 beta- and steroid delta-isomerase 1; si-FGF21: siRNA-FGF21. SR-BI: scavenger receptor class B member 1; SREBP2: sterol regulatory element binding transcription factor 2. $\mathrm{E}_{2}$ : estradiol; P4: progesterone;

p21: p21(RAC1) activated kinase 3. Cyclin B: cell cycle protein B; Cyclin D: cell cycle protein D; Cyclin E: cell cycle protein E;

\section{Declarations}

\section{Ethics approval and consent to participate}

These studies were approved by Northwest Agriculture and Forestry University Animal Research Ethics Committee (Yangling, Shaanxi, China).

\section{Consent for publication}

Not applicable.

\section{Competing interests}

The authors declare that they have no conflict of interest.

\section{Availability of data and material}


The data sets used and analyzed during the current study are available from the corresponding author on reasonable request.

\section{Funding}

This work is supported by grants from the National Natural Science Foundation of China (N0.31802047), the Major Project of breeding new varieties of genetically modified organisms (NO.2016ZX08006003).

\section{Authors' contributions}

HYM and CGY conceived and designed the experiments; HYM, ZXG and SSJ performed the experiments; LYK and HL contributed reagents/materials/analysis tool; YGS managed the project; HYM wrote the manuscript; GL and PWJ modified the manuscript. The authors read and approved the final manuscript.

\section{Acknowledgements}

We gratefully acknowledge all the teachers and students in Laboratory of Animal Fat Deposition \& Muscle Development of Northwest A\&F University.

\section{References}

1. Geng L, Lam KSL, Xu A. The therapeutic potential of FGF21 in metabolic diseases: from bench to clinic. Nat Rev Endocrinol. 2020;16(11):654-67.

2. BonDurant LD, Ameka M, Naber MC, Markan KR, Idiga So, Acevedo MR, et al. FGF21 Regulates Metabolism Through Adipose-Dependent and -Independent Mechanisms. Cell Metab. 2017;25(4):935-44 e4.

3. Bhattacharya A, Sun S, Wang H, Liu M, Long Q, Yin L, et al. Hepatic Sel1L-Hrd1 ER-associated degradation (ERAD) manages FGF21 levels and systemic metabolism via CREBH. EMBO J. 2018;37:22.

4. Hu Y, Liu HX, Jena PK, Sheng L, Ali MR, Wan YY. miR-22 inhibition reduces hepatic steatosis via FGF21 and FGFR1 induction. JHEP Rep. 2020;2(2):100093.

5. Yu X, Li Y, Jiang G, Fang J, You Z, Shao G, et al. FGF21 promotes non-small cell lung cancer progression by SIRT1/PI3K/AKT signaling. Life Sci. 2021;269:118875.

6. Li Y, Huang J, Jiang Z, Jiao Y, Wang H. FGF21 inhibitor suppresses the proliferation and migration of human umbilical vein endothelial cells through the eNOS/PI3K/AKT pathway. Am J Transl Res. 2017;9(12):5299-307.

7. Huang Z, Zhong L, Lee JTH, Zhang J, Wu D, Geng L, et al. The FGF21-CCL11 Axis Mediates Beiging of White Adipose Tissues by Coupling Sympathetic Nervous System to Type 2 Immunity. Cell Metab. 
2017;26(3):493-508 e4.

8. Saatcioglu HD, Cuevas I, Castrillon DH. Control of Oocyte Reawakening by Kit. PLoS Genet. 2016;12(8):e1006215.

9. Douville G, Sirard MA. Changes in granulosa cells gene expression associated with growth, plateau and atretic phases in medium bovine follicles. J Ovarian Res. 2014;7:50.

10. Khan MI, Dias FC, Dufort I, Misra V, Sirard MA, Singh J. Stable reference genes in granulosa cells of bovine dominant follicles during follicular growth, FSH stimulation and maternal aging. Reprod Fertil Dev. 2016;28(6):795-805.

11. Simpson ER. Models of aromatase insufficiency. Semin Reprod Med. 2004;22(1):25-30.

12. Gruber CJ, Tschugguel W, Schneeberger C, Huber JC. Production and actions of estrogens. N Engl J Med. 2002;346(5):340-52.

13. Marylise HS, Belinda R, Brenna K, Jean G, Marie CJIJoMS. The Interplay between Glucose-Regulated Protein 78 (GRP78) and Steroids in the Reproductive System. 2018;19(7):1842.

14. Long B, Chu G, Wang W, Xiang A, Yang GJT. BAMBI promotes porcine granulosa cell steroidogenesis involving TGF- $\beta$ signaling. 2017;100:24-31.

15. Chou $\mathrm{CH}$, Chen MJ. The Effect of Steroid Hormones on Ovarian Follicle Development. Vitam Horm. 2018;107:155-75.

16. Shi S, Zhou X, Li J, Zhang L, Hu Y, Li Y, et al. MiR-214-3p promotes proliferation and inhibits estradiol synthesis in porcine granulosa cells. J Anim Sci Biotechnol. 2020;11:94.

17. Barbe A, Rame C, Mellouk N, Estienne A, Bongrani A, Brossaud A, et al. Effects of Grape Seed Extract and Proanthocyanidin B2 on In Vitro Proliferation, Viability, Steroidogenesis, Oxidative Stress, and Cell Signaling in Human Granulosa Cells. Int J Mol Sci. 2019;20(17).

18. Lv X, He C, Huang C, Wang H, Hua G, Wang Z, et al. Timely expression and activation of YAP1 in granulosa cells is essential for ovarian follicle development. FASEB J. 2019;33(9):10049-64.

19. Skowronski MT, Mlotkowska P, Tanski D, Lepiarczyk E, Kempisty B, Jaskiewicz L, et al. Pituitary Hormones (FSH, LH, PRL, and GH) Differentially Regulate AQP5 Expression in Porcine Ovarian Follicular Cells. Int J Mol Sci. 2019;20(19).

20. Liu Y, Yang Y, Li W, Ao H, Zhang Y, Zhou R, et al. Effects of melatonin on the synthesis of estradiol and gene expression in pig granulosa cells. J Pineal Res. 2019;66(2):e12546.

21. Richani D, Gilchrist RB. The epidermal growth factor network: role in oocyte growth, maturation and developmental competence. Hum Reprod Update. 2018;24(1):1-14.

22. Owen BM, Bookout AL, Ding X, Lin VY, Atkin SD, Gautron L, et al. FGF21 contributes to neuroendocrine control of female reproduction. Nat Med. 2013;19(9):1153-6.

23. Singhal G, Douris N, Fish AJ, Zhang X, Adams AC, Flier JS, et al. Fibroblast growth factor 21 has no direct role in regulating fertility in female mice. Mol Metab. 2016;5(8):690-8.

24. Zhuo Y, Hua L, Feng B, Jiang X, Li J, Jiang D, et al. Fibroblast growth factor 21 coordinates adiponectin to mediate the beneficial effects of low-protein diet on primordial follicle reserve. 
EBioMedicine. 2019;41:623-35.

25. Dai H, Hu W, Zhang L, Jiang F, Mao X, Yang G, et al. FGF21 facilitates autophagy in prostate cancer cells by inhibiting the PI3K-Akt-mTOR signaling pathway. Cell Death Dis. 2021;12(4):303.

26. Wu S, Levenson A, Kharitonenkov A, De Luca F. Fibroblast growth factor 21 (FGF21) inhibits chondrocyte function and growth hormone action directly at the growth plate. J Biol Chem. 2012;287(31):26060-7.

27. Bai L, Chu G, Wang W, Xiang A, Yang G. BAMBI promotes porcine granulosa cell steroidogenesis involving TGF-beta signaling. Theriogenology. 2017;100:24-31.

28. Fang L, Yan Y, Wang S, Guo Y, Li Y, Jia Q, et al. High ovarian GDF-8 levels contribute to elevated estradiol production in ovarian hyperstimulation syndrome by stimulating aromatase expression. Int J Biol Sci. 2021;17(9):2338-47.

29. Perego MC, Caloni F, Cortinovis C, Schutz LF, Albonico M, Tsuzukibashi D, et al. Influence of a Roundup formulation on glyphosate effects on steroidogenesis and proliferation of bovine granulosa cells in vitro. Chemosphere. 2017;188:274-9.

30. Chen S, Wang F, Liu Z, Zhao Y, Jiang Y, Chen L, et al. Brain-derived neurotrophic factor promotes proliferation and progesterone synthesis in bovine granulosa cells. J Cell Physiol. 2019;234(6):8776-87.

31. Hua L, Feng B, Huang L, Li J, Luo T, Jiang X, et al. Time-restricted feeding improves the reproductive function of female mice via liver fibroblast growth factor 21. Clin Transl Med. 2020;10(6):e195.

32. Yu J, Zhang L, Li Y, Zhu X, Xu S, Zhou XM, et al. The Adrenal Lipid Droplet is a New Site for Steroid Hormone Metabolism. Proteomics. 2018;18(23):e1800136.

33. Han HS, Choi BH, Kim JS, Kang G, Koo SH. Hepatic Crtc2 controls whole body energy metabolism via a miR-34a-Fgf21 axis. Nat Commun. 2017;8(1):1878.

34. Yenuganti VR, Viergutz T, Vanselow J. Oleic acid induces specific alterations in the morphology, gene expression and steroid hormone production of cultured bovine granulosa cells. Gen Comp Endocrinol. 2016;232:134-44.

35. Ellinwood WE, McClellan MC, Brenner RM, Resko JA. Estradiol synthesis by fetal monkey ovaries correlates with antral follicle formation. Biol Reprod. 1983;28(2):505-16.

36. Lu W, Li X, Luo Y. FGF21 in obesity and cancer: New insights. Cancer Lett. 2021;499:5-13.

37. Koliadi A, Nilsson C, Holmqvist M, Holmberg L, de La Torre M, Warnberg F, et al. Cyclin B is an immunohistochemical proliferation marker which can predict for breast cancer death in low-risk node negative breast cancer. Acta Oncol. 2010;49(6):816-20.

38. Deng T, Yan G, Song X, Xie L, Zhou Y, Li J, et al. Deubiquitylation and stabilization of p21 by USP11 is critical for cell-cycle progression and DNA damage responses. Proc Natl Acad Sci U S A. 2018;115(18):4678-83.

39. Kuroda M, Muramatsu R, Maedera N, Koyama Y, Hamaguchi M, Fujimura H, et al. Peripherally derived FGF21 promotes remyelination in the central nervous system. J Clin Invest. 2017;127(9):3496-509. 

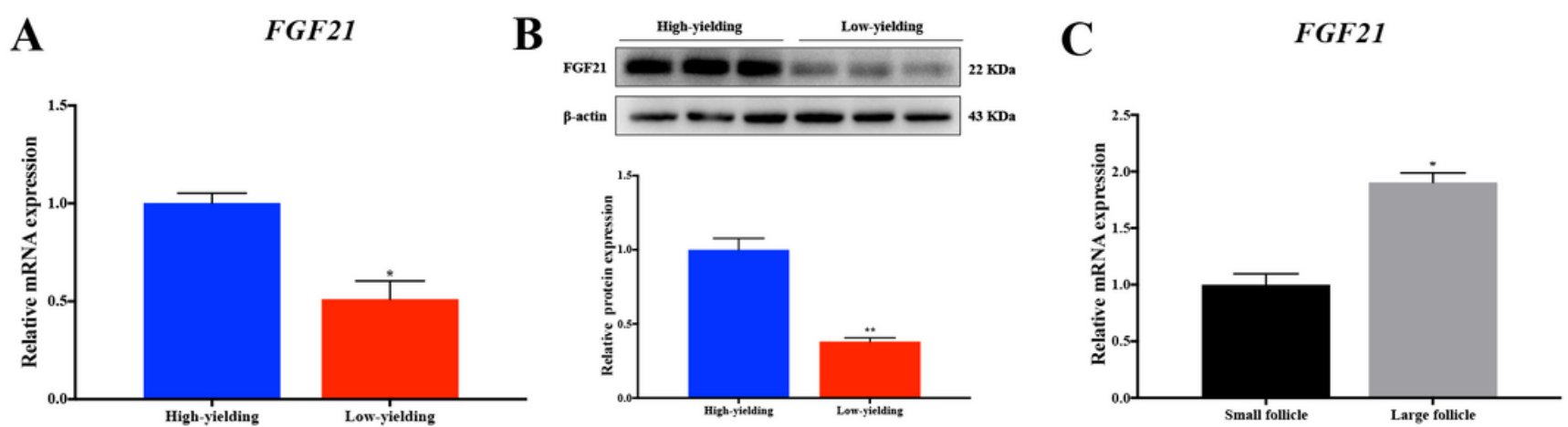

D
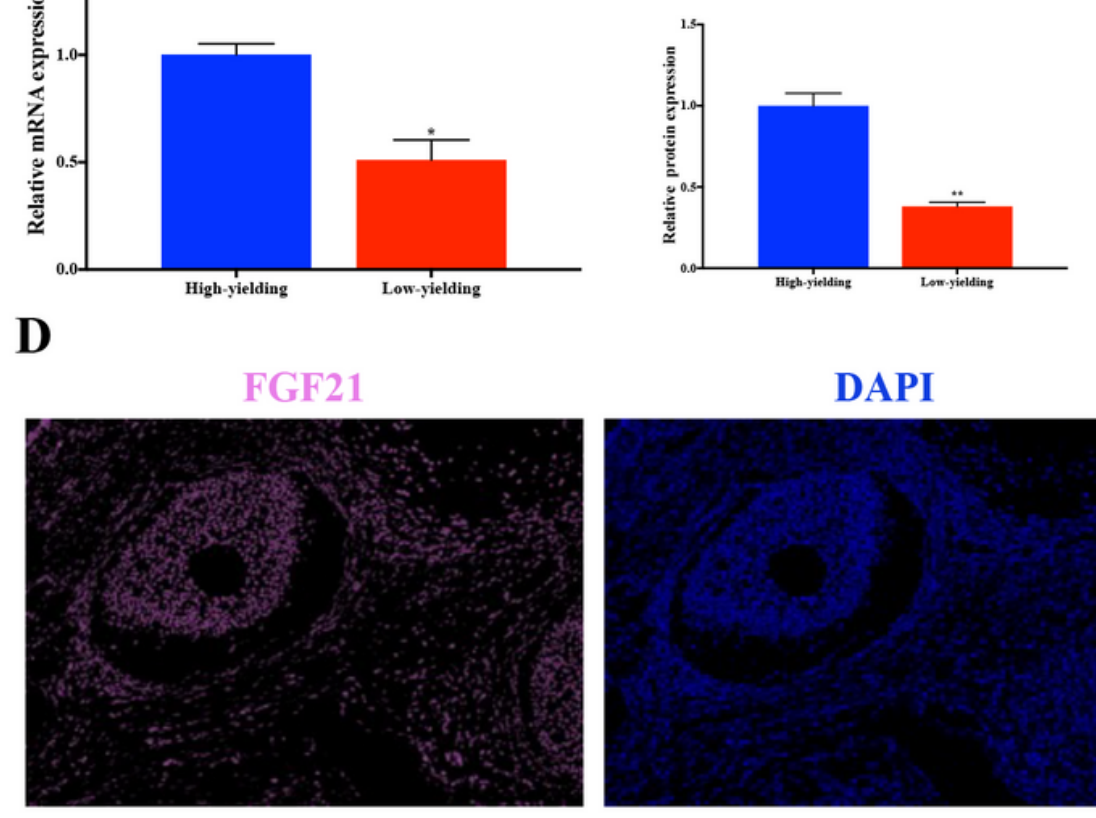

DAPI
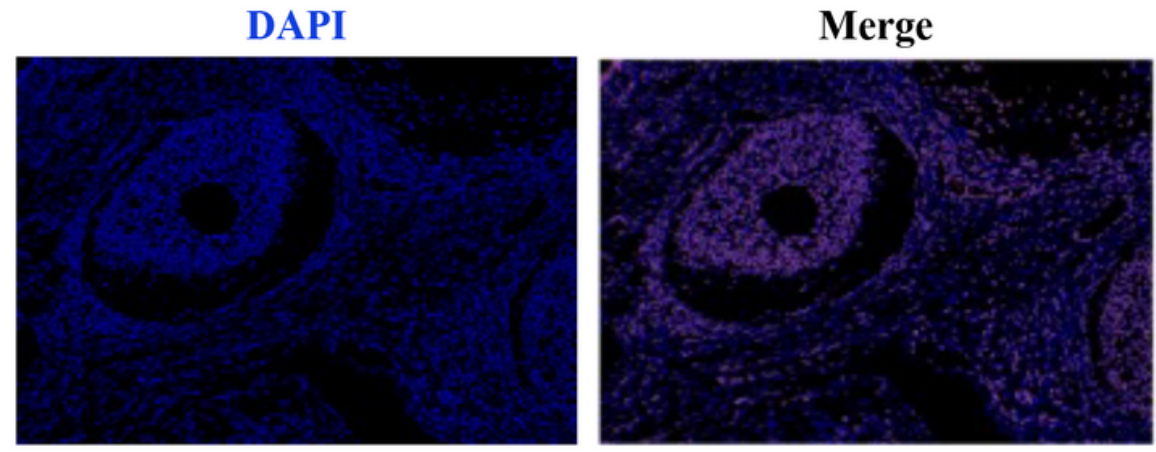

\section{Figure 1}

The expression of FGF21 in porcine ovary. A, mRNA levels of FGF21 in high- and low-yileding porcine ovarian ( $n=3)$. B, protein levels of FGF21 in high- and low-yileding porcine ovarian $(n=3)$. C, FGF21 mRNA levels in GCs of large follicles (diameters $>6 \mathrm{~mm}$ ) and GCs of small follicles (diameters $<3 \mathrm{~mm})(\mathrm{n}=3)$. $D$, immunohistochemical staining of FGF21 and DAPI (nuclei) on porcine ovary $(n=3)$. Data represent the mean \pm SEM. $* p<0,05 ; * *<<0.01$. 

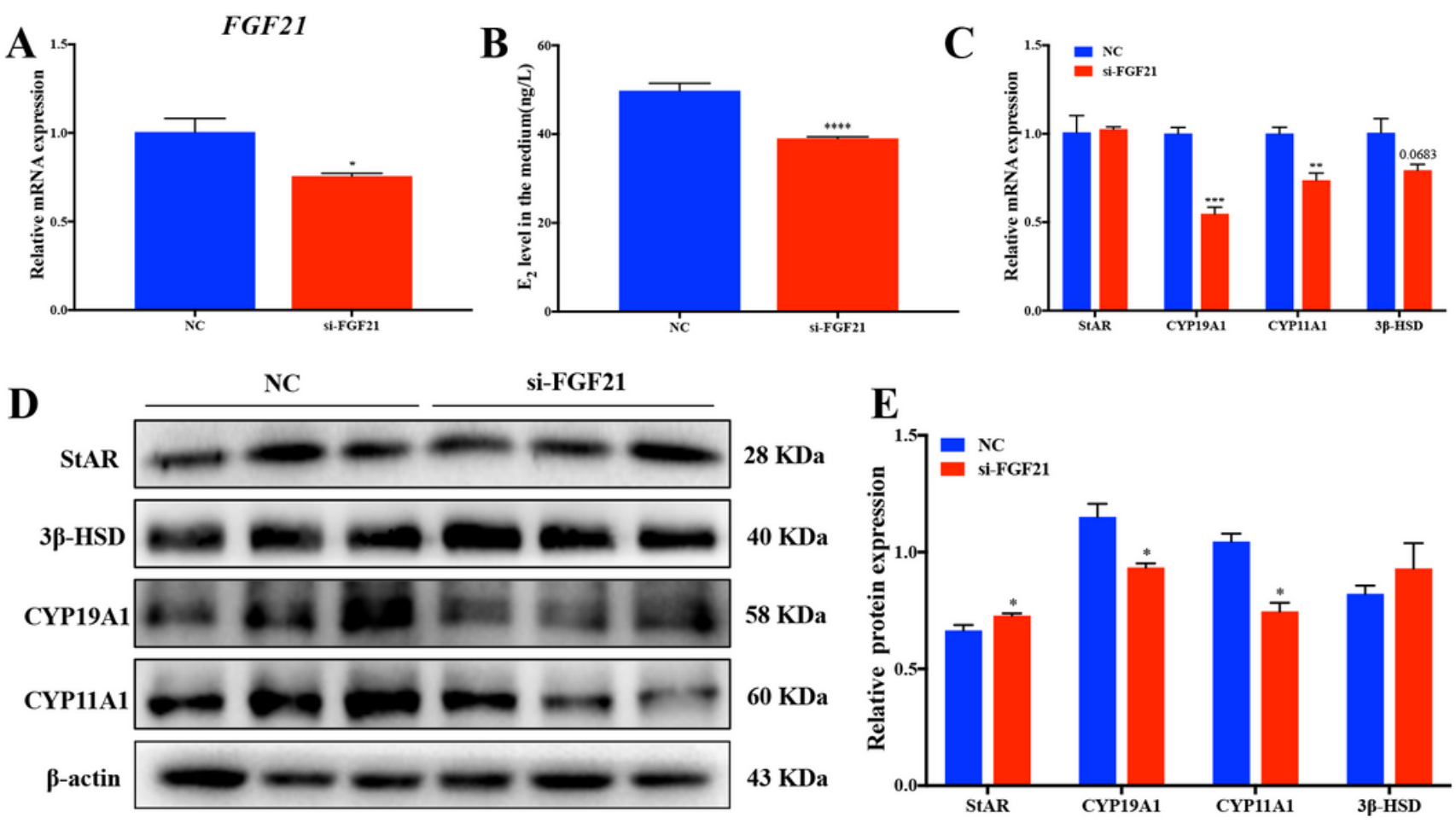

Figure 2

Knockdown of FGF21 inhibits the synthesis of estradiol on granulosa cells. A, knockdown efficiency of FGF21 after transfection with FGF21 siRNA compared to NC $(n=3)$. B, estradiol concentration detected by ELISA $(n=3)$. Culture supernatants collected $24 \mathrm{~h}$ after FGF21 siRNA and NC treatment. C, mRNA levels of StAR, CYP19A1, CYP11A1 and 33-HSD $24 \mathrm{~h}$ after knockdown of FGF21 $(\mathrm{n}=3)$. D, Western blot detection of

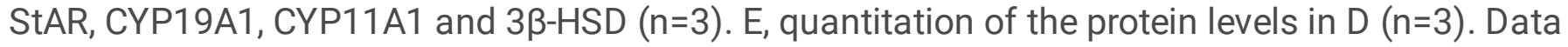
represent the mean \pm SEM. ${ }^{*} p<0,05 ;{ }^{* \star} p<0.01$; ${ }^{* \star *} p<0.001$; ${ }^{* \star \star \star} p<0.0001$. 
A

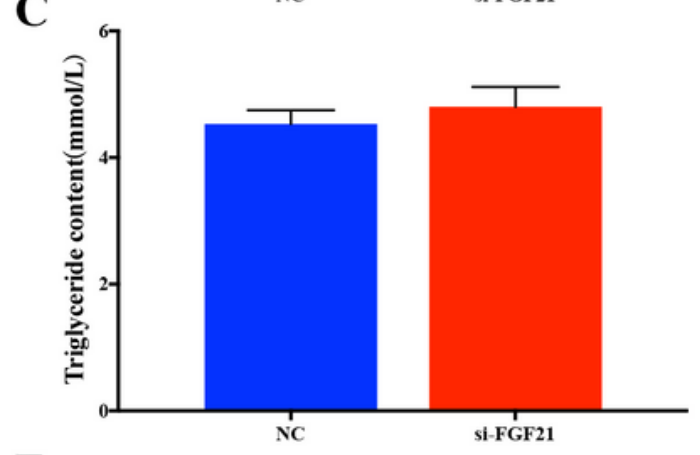

$\mathbf{E}$
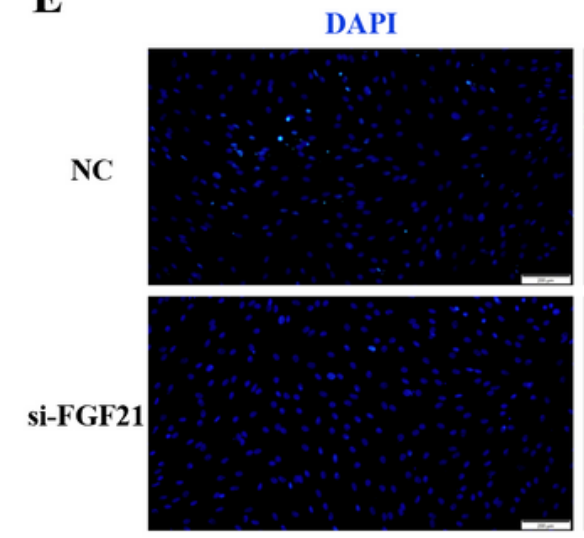

$\mathbf{F}$

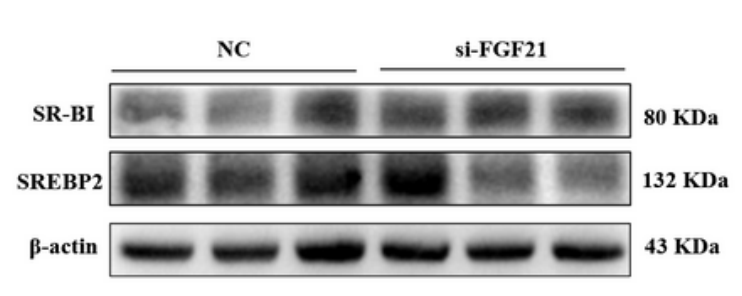

B

D
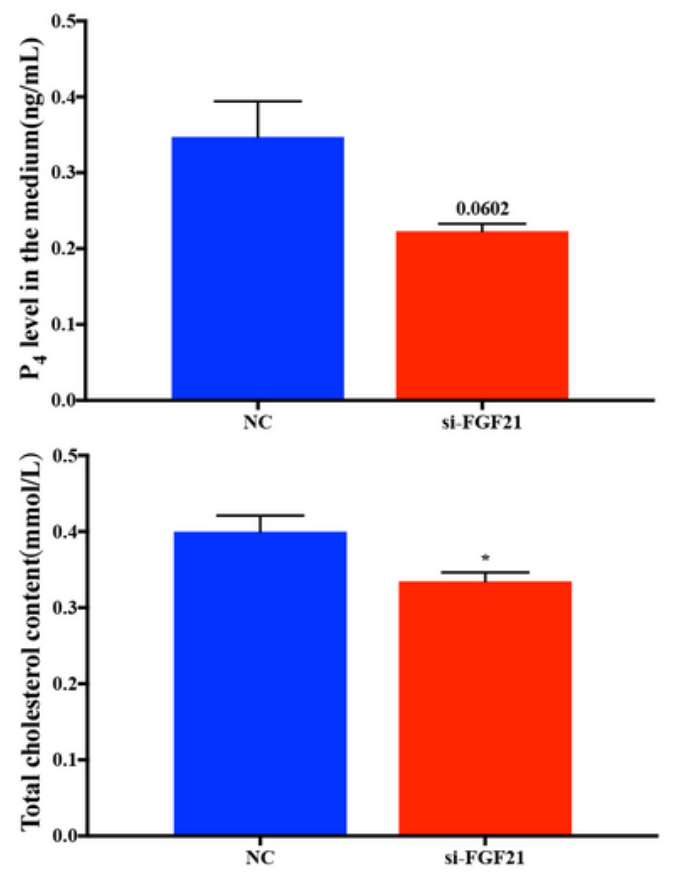

Bodipy
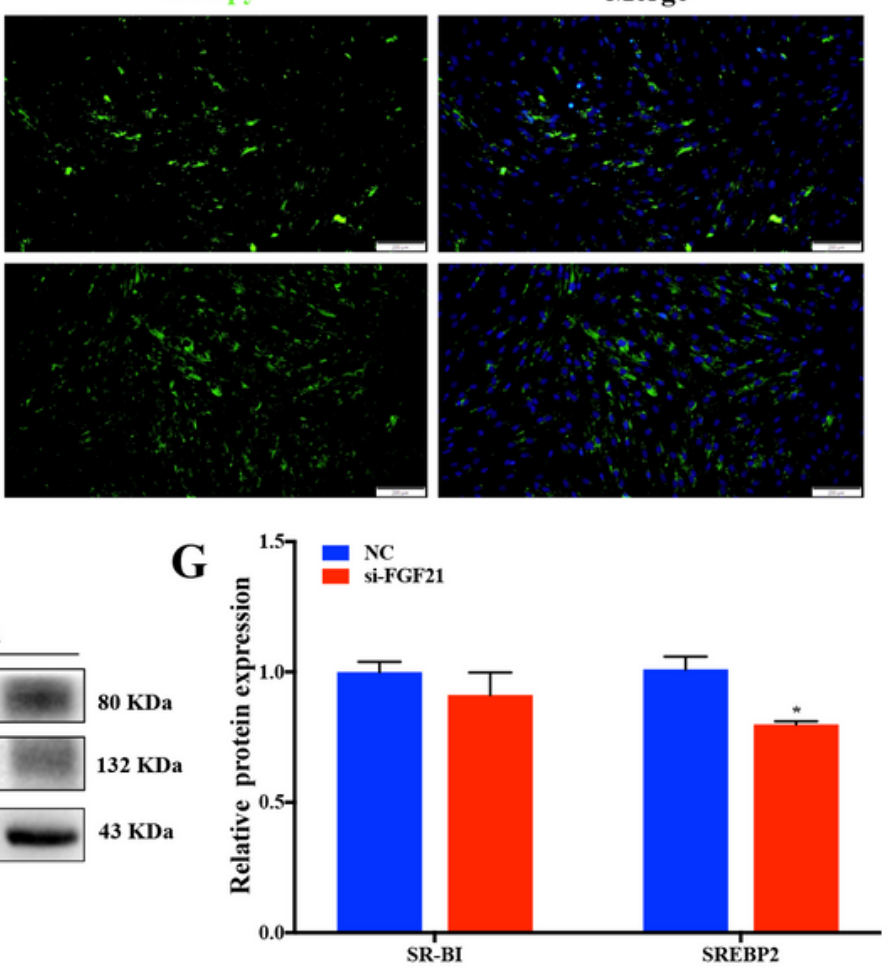

\section{Figure 3}

Knockdown of FGF21 inhibits the cholesterol transport. A, estradiol concentration detected by ELISA $(\mathrm{n}=3)$. Culture supernatants collected $24 \mathrm{~h}$ after FGF21 siRNA and NC treatment. B, progesterone concentration detected by ELISA $(n=3)$. Culture supernatants collected $24 \mathrm{~h}$ after FGF21 siRNA and NC treatment. C, triglyceride levels detected after knockdown of FGF21 $24 \mathrm{~h}(\mathrm{n}=3)$. D, total cholesterol content detected after knockdown of FGF21 24 h ( $n=3)$. E, bodipy staining in GCs $24 \mathrm{~h}$ after knockdown of FGF21 
$(n=3)$. DAPI: nucleus, Scale bar: $200 \mu \mathrm{m}$. F, Western blot detection of SR-BI and SREBP2 $(n=3) . E$, quantitation of the protein levels in $F(n=3)$. Data represent the mean $\pm S E M . * p<0,05 ; * \star p<0.01$; ${ }^{* \star *} p$ $<0.001$;
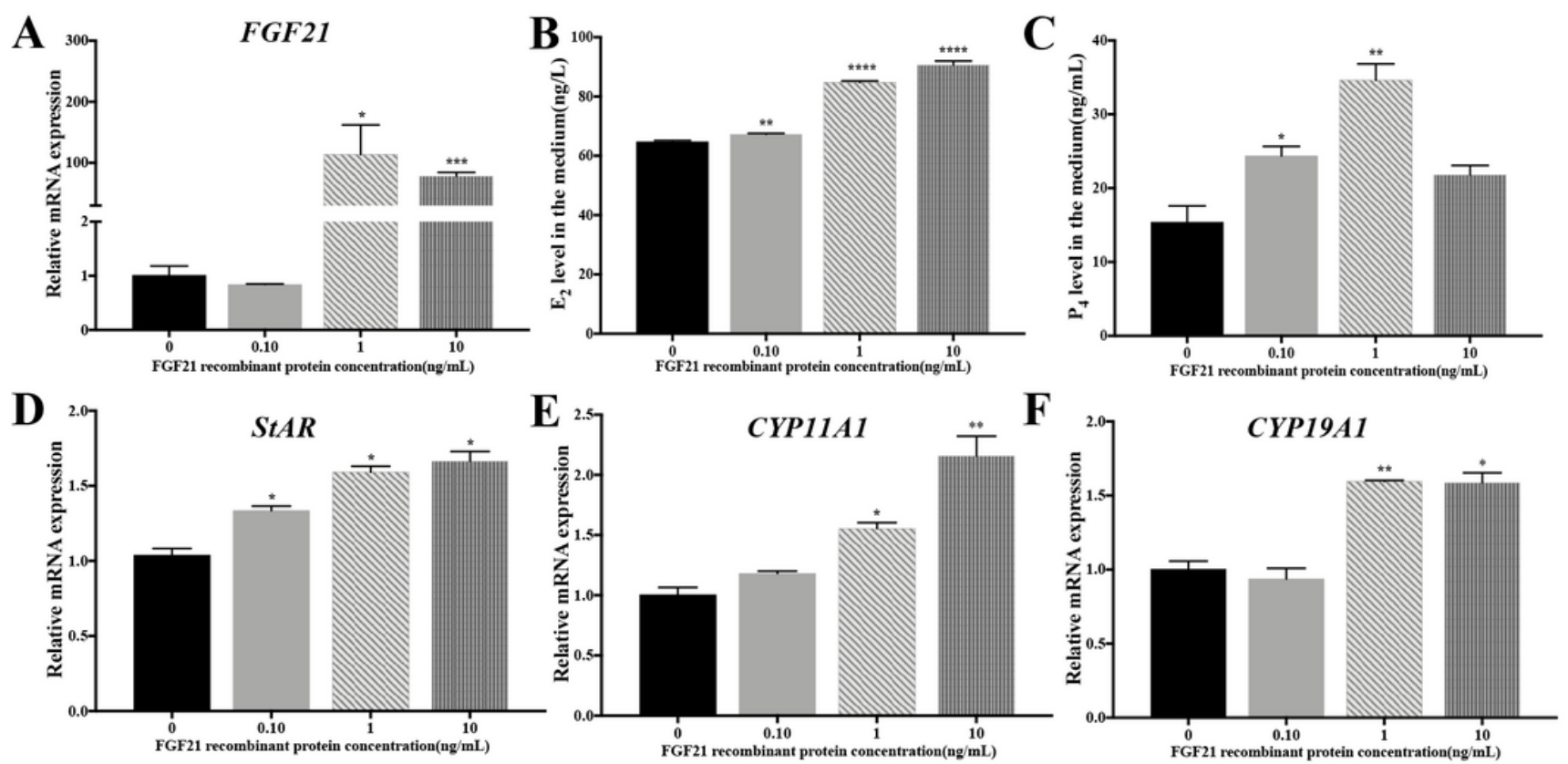

G

0

0.1

1 10

FGF21 (ng/mL)

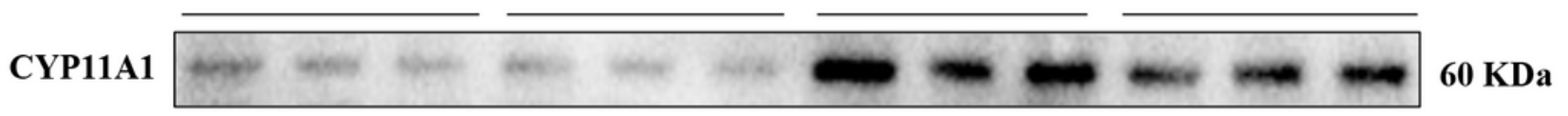

CYP19A1

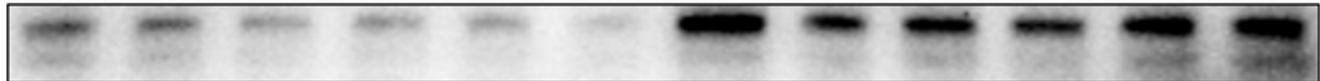

58/53 KDa

StAR

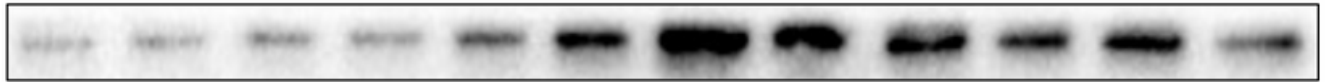

$28 \mathrm{KDa}$

$\beta$-actin

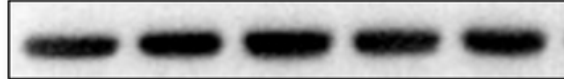

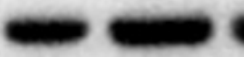

(2)

(6)

$=0$

$43 \mathrm{KDa}$
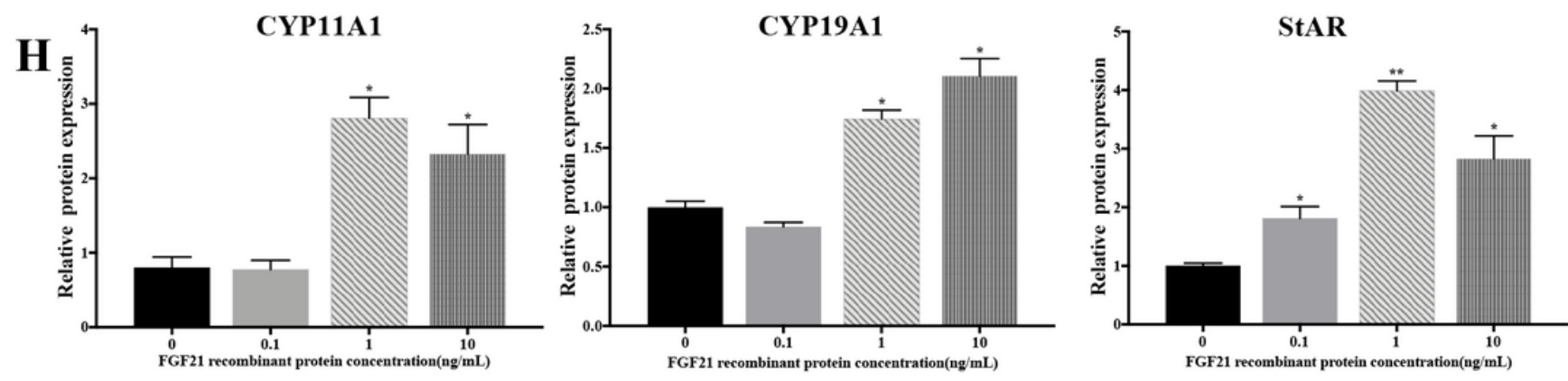

Figure 4

Overexpression of FGF21 promotes the synthesis of estradiol on granulosa cells. A, mRNA levels of FGF21 $24 \mathrm{~h}$ after FGF21 recombinant protein $(0,0.1,1,10 \mathrm{ng} / \mathrm{mL})$ to treat $\mathrm{GCs}(\mathrm{n}=3)$. B, estradiol concentration detected by ELISA $(n=3)$. Culture supernatants collected $24 \mathrm{~h}$ after FGF21 recombinant protein $(0,0.1,1,10 \mathrm{ng} / \mathrm{mL})$ treatment. C, progesterone concentration detected by ELISA $(\mathrm{n}=3)$. Culture 
supernatants collected $24 \mathrm{~h}$ after FGF21 recombinant protein $(0,0.1,1,10 \mathrm{ng} / \mathrm{mL})$ treatment. D, E, F, mRNA levels of StAR, CYP19A1 and CYP11A1 $24 \mathrm{~h}$ after overexpression of FGF21 ( $n=3)$. G, Western blot detection of StAR, CYP19A1 and CYP11A1 $(n=3)$. H, quantitation of the protein levels in $G(n=3)$. Data represent the mean \pm SEM. ${ }^{*} p<0,05 ; * \star p<0.01 ; * \star * p<0.001 ; * \star * * p<0.0001$.

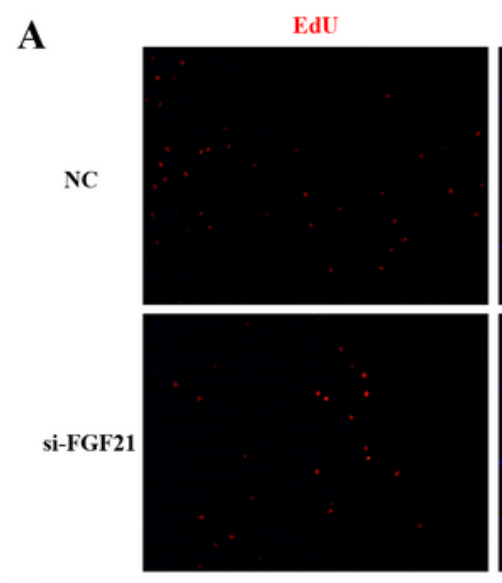

B

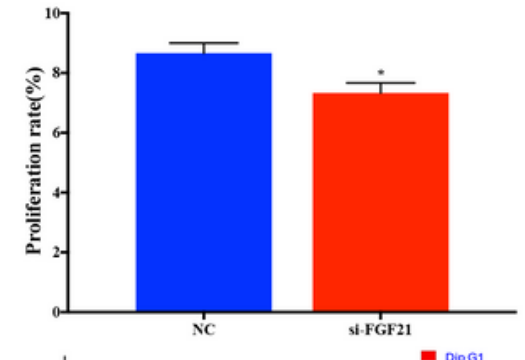

D

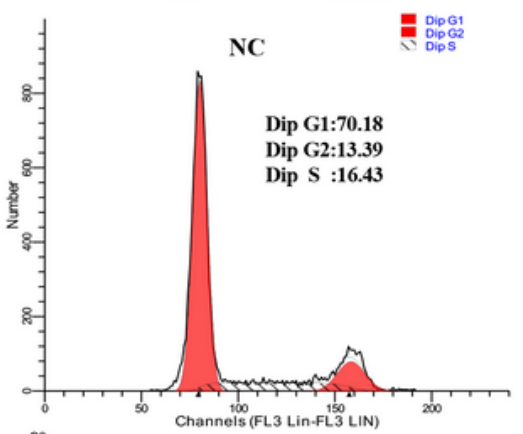

$\mathbf{E}$

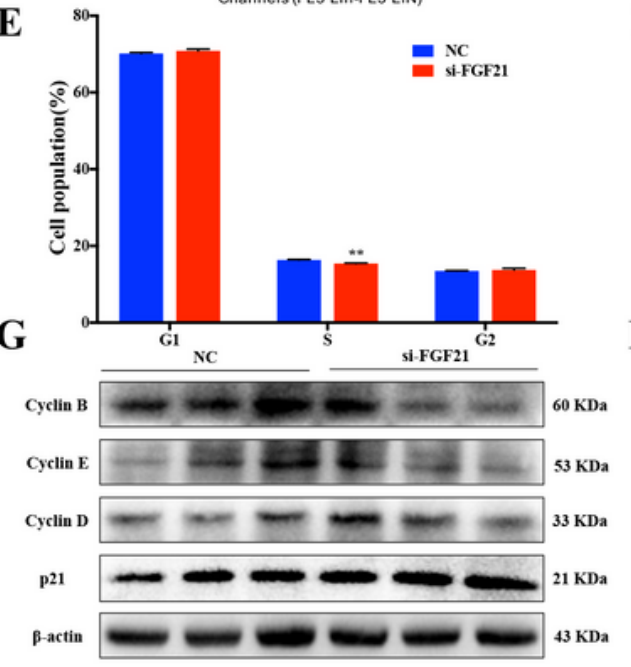

Hochest
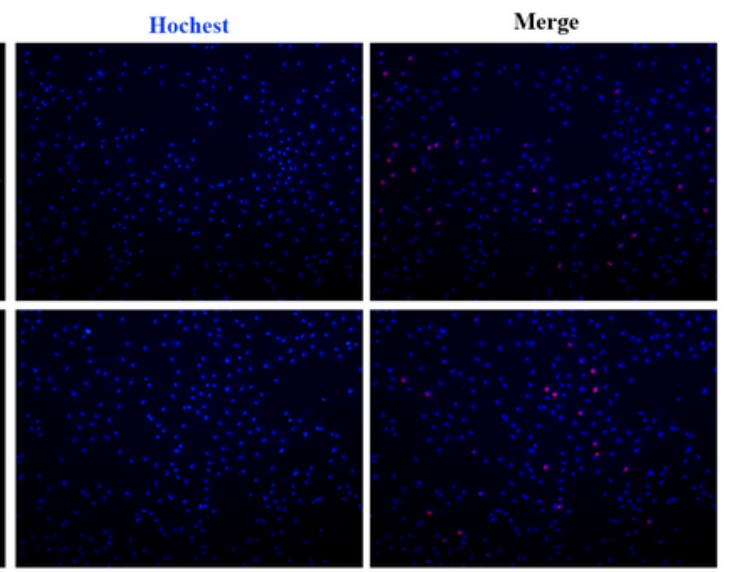

C
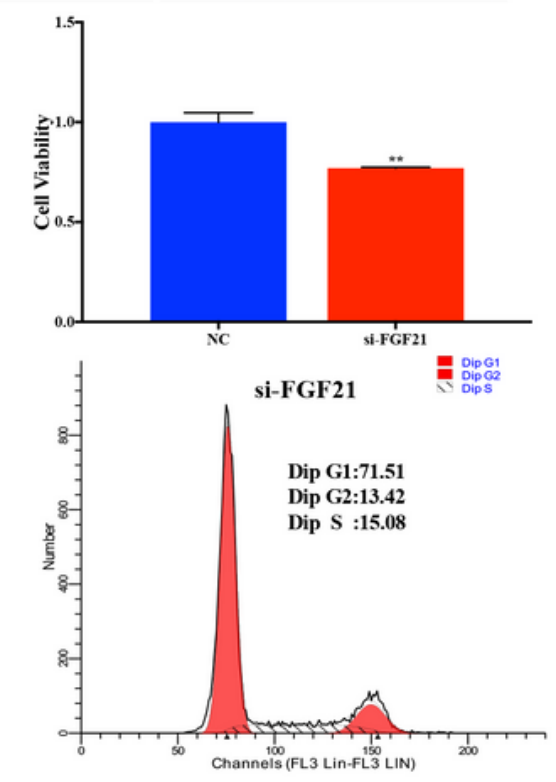

$\mathbf{F}$

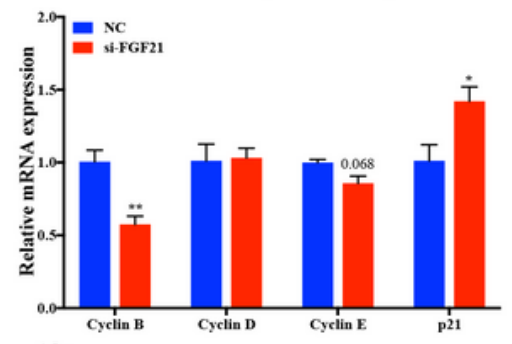

$\mathbf{H}$

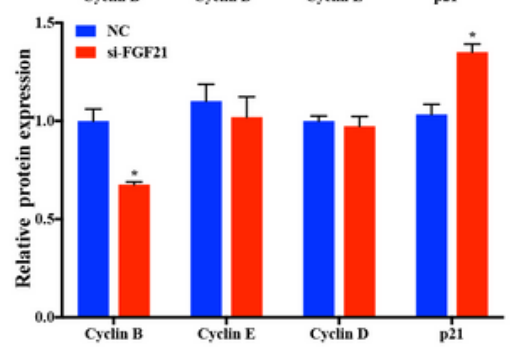

Figure 5 
Knockdown of FGF21 inhibits granulosa cells proliferation. A, EdU and Hochest (nucleus) staining analysis $24 \mathrm{~h}$ after knockdown of FGF21 $(n=3)$. B, percentage of EdU-positive cells/total cells $(n=3)$. C, CCK8 assay detects cell viability $24 \mathrm{~h}$ after knockdown of FGF21 as absorbance value at $450 \mathrm{~nm}$ after incubation with $10 \%$ CCK8 solution for $3 \mathrm{~h}$. D, flow cytometry analysis $24 \mathrm{~h}$ after knockdown of FGF21 $(n=3)$. E, statistical results of flow cytometry $(n=3) . F$, mRNA levels of Cyclin B, Cyclin D, Cyclin E and p21 $24 \mathrm{~h}$ after knockdown of FGF21 ( $n=3)$. G, Western blot detection of Cyclin B, Cyclin D, Cyclin E and p21 24 $h$ after knockdown of FGF21 $(n=3)$. H, quantitation of the protein levels in $G(n=3)$. Data represent the mean \pm SEM. ${ }^{*} p<0,05 ; * \star p<0.01$; 
A
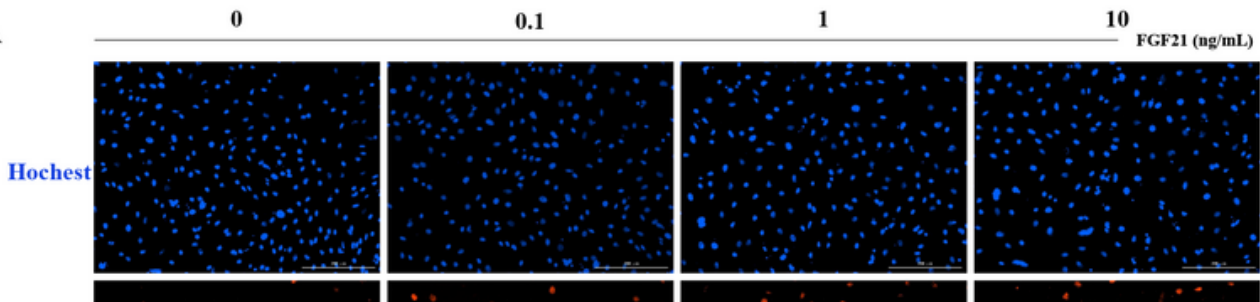

B
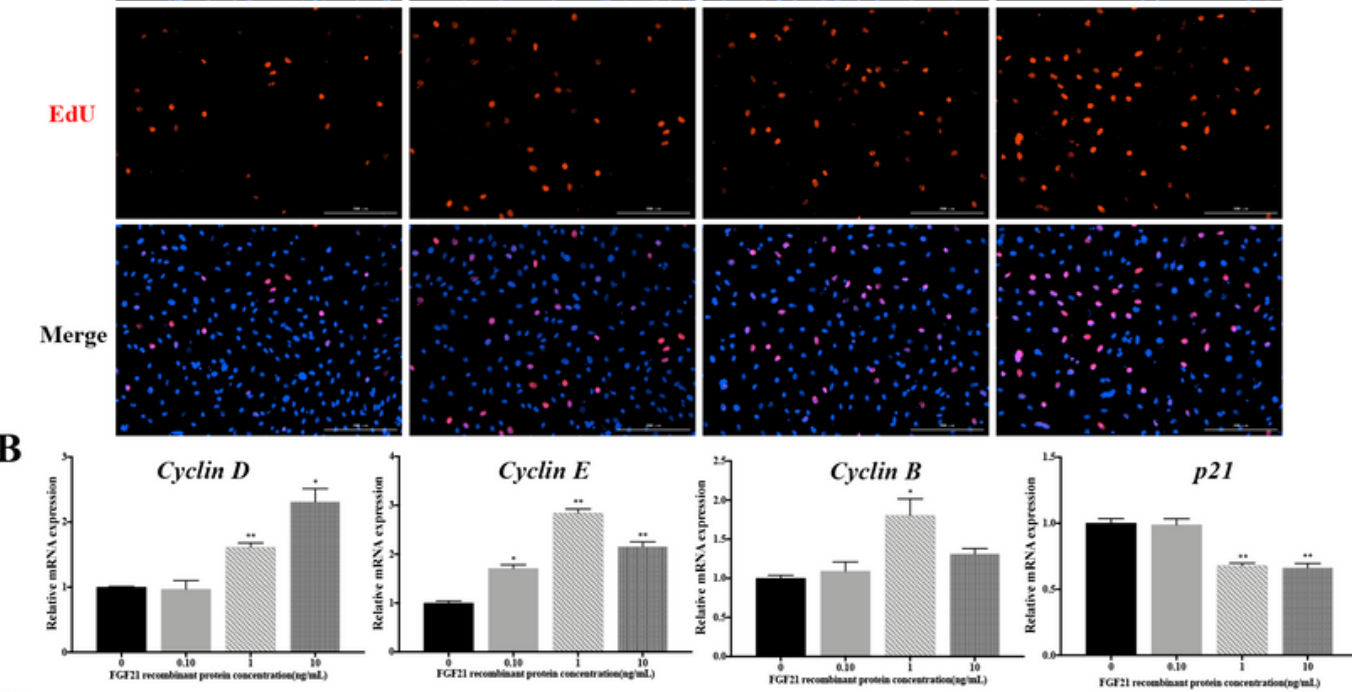

C

0.1
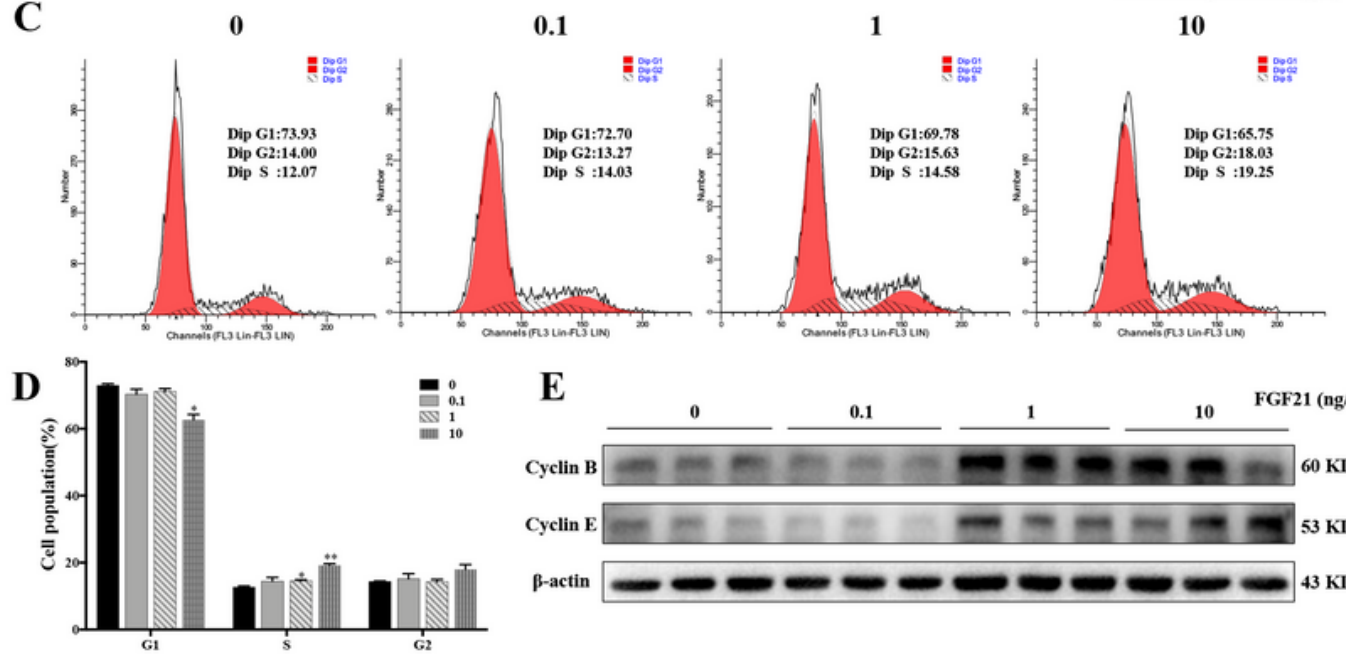

E

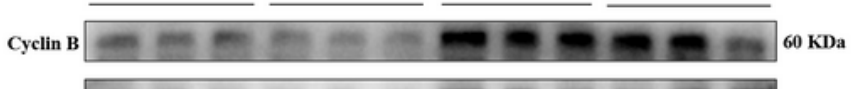

Cyclin E

$\beta$-actin

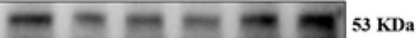

$\mathbf{F}$
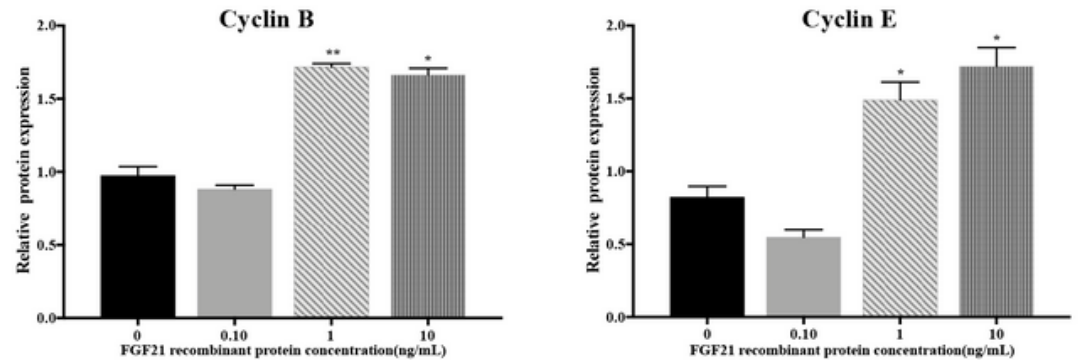

Figure 6

Overexpression of FGF21 promotes granulosa cells proliferation. A, EdU and Hochest (nucleus) staining analysis $24 \mathrm{~h}$ after FGF21 recombinant protein $(0,0.1,1,10 \mathrm{ng} / \mathrm{mL})$ treatment $(\mathrm{n}=3)$. B, mRNA levels of Cyclin B, Cyclin D, Cyclin E and p21 $24 \mathrm{~h}$ after FGF21 recombinant protein $(0,0.1,1,10 \mathrm{ng} / \mathrm{mL})$ treatment $(\mathrm{n}=3)$. C, flow cytometry analysis $24 \mathrm{~h}$ after FGF21 recombinant protein $(0,0.1,1,10 \mathrm{ng} / \mathrm{mL})$ treatment $(\mathrm{n}=3)$. D, flow cytometry analysis $24 \mathrm{~h}$ after FGF21 recombinant protein $(0,0.1,1,10 \mathrm{ng} / \mathrm{mL})$ treatment 
$(n=3)$. E, Western blot detection of Cyclin B and Cyclin E $24 \mathrm{~h}$ after FGF21 recombinant protein $(0,0.1,1,10$ $\mathrm{ng} / \mathrm{mL})$ treatment $(\mathrm{n}=3)$. F, quantitation of the protein levels in $E(n=3)$. Data represent the mean $\pm S E M$.* $p<0,05 ; * \star p<0.01$.

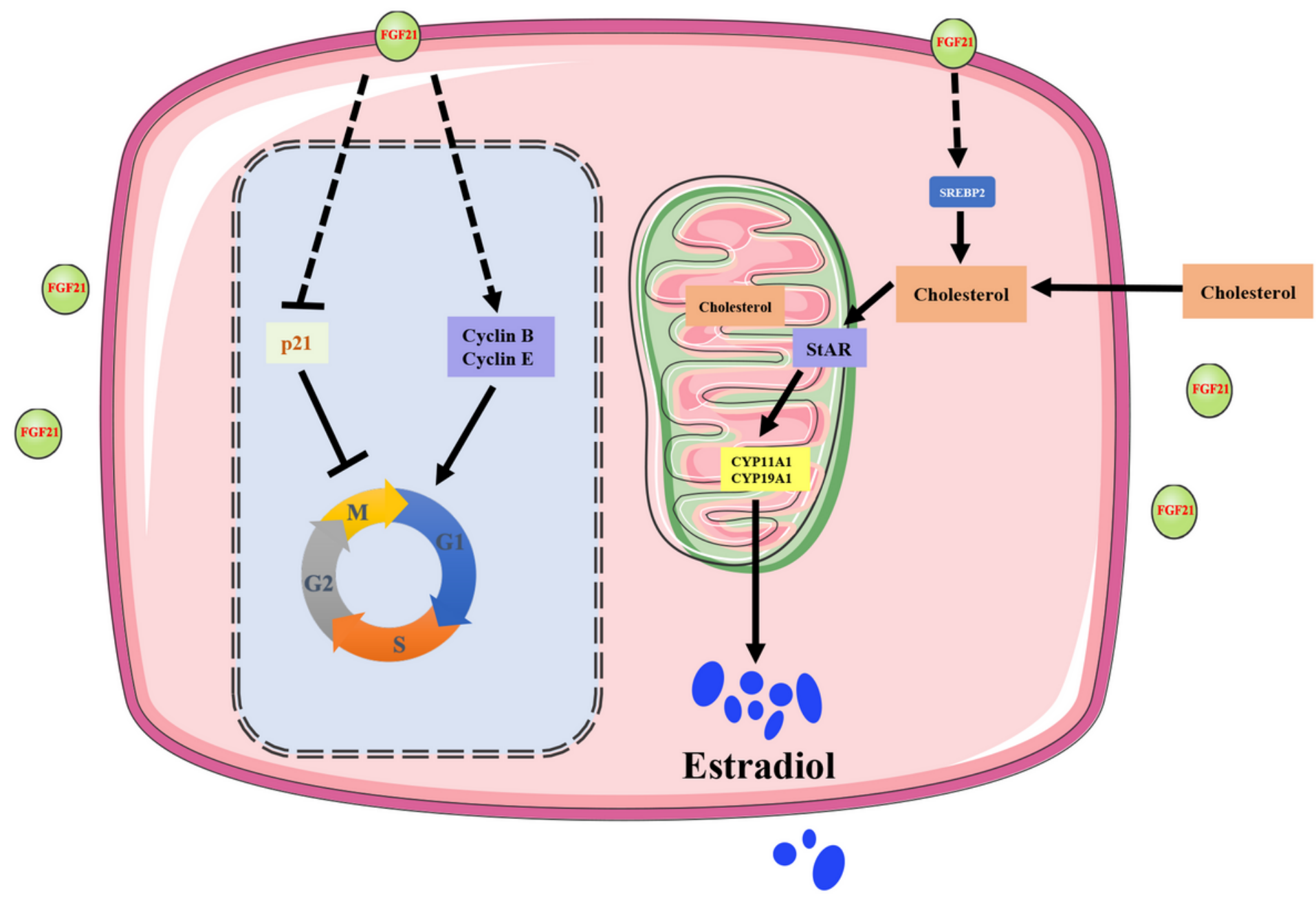

Figure 7

Schematic diagram of FGF21 regulation on porcine GCs proliferation and estradiol synthesis. 